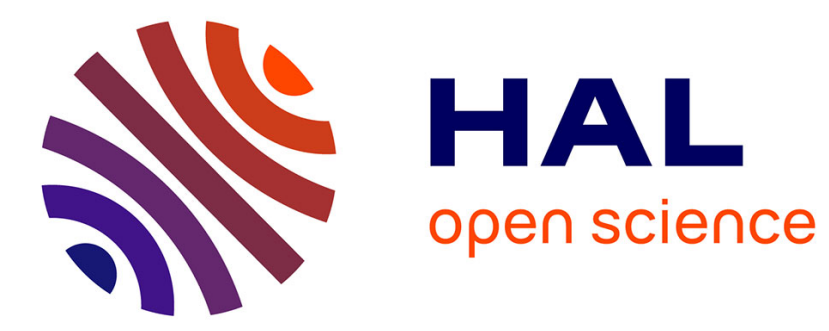

\title{
Elasticity Study on Ag nm-Films
}

H. Mizubayashi, S. Harada, T. Yamaguchi

\section{To cite this version:}

H. Mizubayashi, S. Harada, T. Yamaguchi. Elasticity Study on Ag nm-Films. Journal de Physique IV Proceedings, 1996, 06 (C8), pp.C8-799-C8-802. 10.1051/jp4:19968171 . jpa-00254607

\section{HAL Id: jpa-00254607 https://hal.science/jpa-00254607}

Submitted on 1 Jan 1996

HAL is a multi-disciplinary open access archive for the deposit and dissemination of scientific research documents, whether they are published or not. The documents may come from teaching and research institutions in France or abroad, or from public or private research centers.
L'archive ouverte pluridisciplinaire HAL, est destinée au dépôt et à la diffusion de documents scientifiques de niveau recherche, publiés ou non, émanant des établissements d'enseignement et de recherche français ou étrangers, des laboratoires publics ou privés. 
JOURNAL DE PHYSIQUE IV

Colloque C8, supplément au Journal de Physique III, Volume 6, décembre 1996

\title{
Elasticity Study on Ag nm-Films
}

\author{
H. Mizubayashi, S. Harada and T. Yamaguchi \\ Institute of Materials Science, University of Tsukuba, Tsukuba 305, Japan
}

\begin{abstract}
Young's modulus $E_{\mathrm{f}}$ of polycrystalline Ag nm-films deposited on hydrogen-terminated Si was measured in the film thickness $d$ range between 6 and $50 \mathrm{~nm}$ by means of the vibrating reed method. $E_{\mathrm{f}}$ observed for $d$ above about $20 \mathrm{~nm}$ is slightly higher than the upper bound of Young's modulus expected for polycrystalline Ag bulk-films. On the other hand, with decreasing $d, E_{\mathrm{f}}$ decreases beyond the lower bound of Young's modulus expected for polycrystalline Ag bulk-films. The plausible models to explain these results are discussed.
\end{abstract}

\section{INTRODUCTION}

Ag (sub-) monolayer on $\mathrm{Si}$ have been intensively studied due to scientific as well as semiconductortechnology interest (e.g.,[1-3]). Thicker $\mathrm{Ag} \mathrm{nm-films} \mathrm{may} \mathrm{also} \mathrm{be} \mathrm{interesting} \mathrm{for} \mathrm{the} \mathrm{ULSI} \mathrm{technology}$ because of the low electric resistivity and an atomically sharp $\mathrm{Ag} / \mathrm{Si}$ interface [4], where understanding of mechanical properties is important. However, the knowledge on the mechanical properties of thin films is rather poor because of limited measurement techniques, especially for nm-films (e.g., $[5,6])$. In $[7,8]$ a vibrating reed method has been successively applied to $\mathrm{Al} \mathrm{nm-films} \mathrm{deposited} \mathrm{onto} \mathrm{Si} \mathrm{reeds} \mathrm{and} \mathrm{in} \mathrm{[9]} \mathrm{a}$ similar vibrating reed method, to sub- $\mu \mathrm{m}$ Pt films. For $\mathrm{Al} \mathrm{nm-films} \mathrm{[7,8],} \mathrm{a} \mathrm{strong} \mathrm{decrease} \mathrm{in} \mathrm{Young's}$ modulus is found for thickness below about $10 \mathrm{~nm}$. The phenomena is surmised to reflect increasing influences of grain boundary region and near-interface region with decreasing thickness. On the other hand, it is reported that films with grain size being much larger than thickness can be prepared for very thin $\mathrm{Ag}$ films deposited onto hydrogen (H-) terminated $\mathrm{Si}(111)[10,11]$. For such a film, influences of grain boundary region on the elastic property are expected to be negligible. To pursue further investigation on the elastic property of metal nm-films, we carried out the vibrating reed measurements for $\mathrm{Ag} \mathrm{nm}$-films deposited onto H-terminated Si.

\section{EXPERIMENT}

A Strip of a floating zone Si single crystal of size $3 \times 3 \times 22 \mathrm{~mm}^{3}$ was polished into a reed of $120 \mu \mathrm{m}$ thick and $15 \mathrm{~mm}$ gage length with one end left thick for clamping. The top mirror surface and the long axis of the reed are (100) and $\langle 100\rangle$, respectively. The reed substrates were used after H-termination. A Ag film was deposited on top of the mirror surface of a reed at room temperature in a vacuum of $4 \sim 6 \times 10^{-5} \mathrm{~Pa}$ with a deposition rate below $0.3 \mathrm{~nm} / \mathrm{s}$ by an evaporation method. In the present work, the $\mathrm{Ag}$ films in the thickness range between about 6 and $50 \mathrm{~nm}$ were prepared. After deposition, a reed was transferred to a measurement chamber in the atmosphere and the vibrating reed measurements were carried out in a vacuum of $10^{-4} \sim 10^{-3} \mathrm{~Pa}$. In contrast to $\mathrm{Al} \mathrm{nm}$-films which show an effect of rapid oxidation, a change in the resonant frequency $f, \Delta f$, of the reed due to deposition of a $\mathrm{Ag} \mathrm{nm}$-film remained constant during the vibrating reed measurements reflecting slow oxidation for $\mathrm{Ag} \mathrm{nm}$-films $[7,8]$.

The SEM and AFM observations for the $6 \mathrm{~nm}$-film on H-terminated Si showed the followings: In the SEM observation, the $6 \mathrm{~nm}$-film is a smooth film, where small holes of sub- $\mu \mathrm{m}$ in diameter with the area 
density of about $1 /\left(400 \mu \mathrm{m}^{2}\right)$ were observed. Cracks of typically $0.3 \times 20 \mu \mathrm{m}^{2}$ were also observed, suggesting that internal stress in the film is tension. The fractional area of the holes and cracks is negligibly small. The AFM observation showed that the mean grain size is about $100 \mathrm{~nm}$, and the asperity height lies between about 5 and $10 \mathrm{~nm}$, i.e., the asperity ratio lies between about $5 / 100$ and 10/100.

The X-ray diffraction was made by a conventional $\theta-2 \theta$ scan using $\mathrm{Cu}-\mathrm{K} \alpha$ from a X-ray tube, where $\mathrm{Ag}(111), \mathrm{Ag}(200), \mathrm{Ag}(220)$ and $\mathrm{Si}(400)$ reflections were observed: $\mathrm{Si}(400)$ reflection from a reed substrate is very sharp and strong. Diffraction peaks of $\mathrm{Ag}$ films are broad and weak, and decrease in the order of $\operatorname{Ag}(111), \operatorname{Ag}(200)$ and $\mathrm{Ag}(220)$. Figure 1(a) shows the ratio of the peak height $I_{(200)}$ of $A g(200)$ reflection to $\mathrm{I}_{(111)}$ of $\mathrm{Ag}(111)$ reflection which were observed for $\mathrm{Ag} \mathrm{nm}$-films on H-terminated $\mathrm{Si}$, where the values of $\mathrm{I}_{(200)} / \mathrm{I}_{(111)}$ are found in the range between nearly zero and about 0.2 . The $X$-ray results suggest that a Ag nm-film on H-terminated $\mathrm{Si}$ is composed of the $\langle 111\rangle_{-}$, the $\langle 100\rangle_{-}$and the $\langle 100\rangle_{-}$ oriented crystallites as the major, the minor and the very-minor constituents, respectively, although their fractions are somewhat different among the films. Figure 1(b) shows the lattice spacing $a_{0}$ of $\mathrm{Ag}$ measured along the normal direction of the film plane which was evaluated from Ag(111) reflection, where $\operatorname{Si}(400)$ reflection was used as reference. The observed values of $a_{0}$ appear to be slightly smaller than $a_{0}$ reported for bulk $\mathrm{Ag}$ and remain unchanged in the present thickness range.

For the film-substrate system where a film with thickness $d$ is deposited onto one surface of the reed substrate with rectangular cross section with thickness $b$, the change in the resonant frequency $\Delta f$ expected after the deposition of the film can be related to Young's modulus of the detached film $E_{\mathrm{f}}$ by

$$
E_{\mathrm{f}}=\left(E_{\mathrm{s}} / 3\right)\left[2(\Delta f / f) /(d / b)+\left(\rho_{\mathrm{f}} / \rho_{\mathrm{s}}\right)\right]\left[\left(1-v_{\mathrm{f}}^{2}\right) /\left(1-v_{\mathrm{f}} v_{\mathrm{s}}\right)\right],
$$

where $E_{\mathrm{s}}$ denotes Young's modulus of the substrate, $\rho_{\mathrm{f}}$ and $\rho_{\mathrm{s}}$ are the volume density of the film and that of the substrate, $v_{\mathrm{f}}$ and $v_{\mathrm{s}}$ are Poisson ratio of the film and that of the substrate, respectively [7,12]. In the present work, $E_{\mathrm{f}}$ of the Ag film was accounted for from equation (1) using the experimental values of $\Delta f / f, d$ and $b$, and the values of $E_{\mathrm{s}}, \rho_{\mathrm{f}}, \rho_{\mathrm{s}}, v_{\mathrm{f}}$ and $v_{\mathrm{s}}$ reported in a literature.

During measurements of the resonant frequency $f$ of the reed, the reed temperature was controlled within $\pm 0.01 \mathrm{~K}$ at a given temperature, nominally at $300.00 \mathrm{~K}$ here (see [7] for the measurement procedure to find the intrinsic value of $f$ ). $\Delta f / f$ found after deposition of $\mathrm{Ag}$ films was, e.g., $-(72 \pm 3) \times 10^{-6}$ for the $6 \mathrm{~nm}$-film and $-(275 \pm 5) \times 10^{-6}$ for the $22 \mathrm{~nm}$-film. Thickness $d$ of a $\mathrm{Ag}$ film was estimated from the area of the film which was separately monitored and $\rho_{f}$ reported for bulk $\mathrm{Ag}$, where the measurement accuracy of $d$ was, e.g., within $\pm 15 \%$ for the $6 \mathrm{~nm}$-film and \pm $5 \%$ for the $22 \mathrm{~nm}$-film. The experimental accuracy of $E_{\mathrm{f}}$ accounted for from that of $\Delta f l f$ and $d$ was, e.g., within about $\pm 20 \%$ for the $6 \mathrm{~nm}$-film and $\pm 10 \%$ for the $22 \mathrm{~nm}$-film, respectively.

Figure 2 shows the thickness $d$ dependence of Young's modulus $E_{\mathrm{f}}$ observed for $\mathrm{Ag}$ nm-films on $\mathrm{H}-\mathrm{Si}$, where the experimental accuracy of $E_{\mathrm{f}}$ is within about \pm $1 \times 10^{10} \mathrm{~Pa}$. The horizontal lines shown with the crystallographic directions are the values of Young's modulus reported for bulk Ag single crystals. The bold arrow a denotes $E_{\mathrm{f}}$ expected for a polycrystalline $\mathrm{Ag}$ bulk-film which is composed of the <111>-oriented crystallites alone (the $<111>$-oriented model-film and so on, hereafter). The bold arrows $\mathbf{b}$ and $\mathbf{c}$ denote $E_{\mathrm{f}}$ expected for the $\langle 110\rangle$ - and the $\langle 100\rangle$-oriented model-films, respectively. In Fig.2, the values of $E_{\mathrm{f}}$ observed for the $\mathrm{Ag} \mathrm{nm}$-films show the general

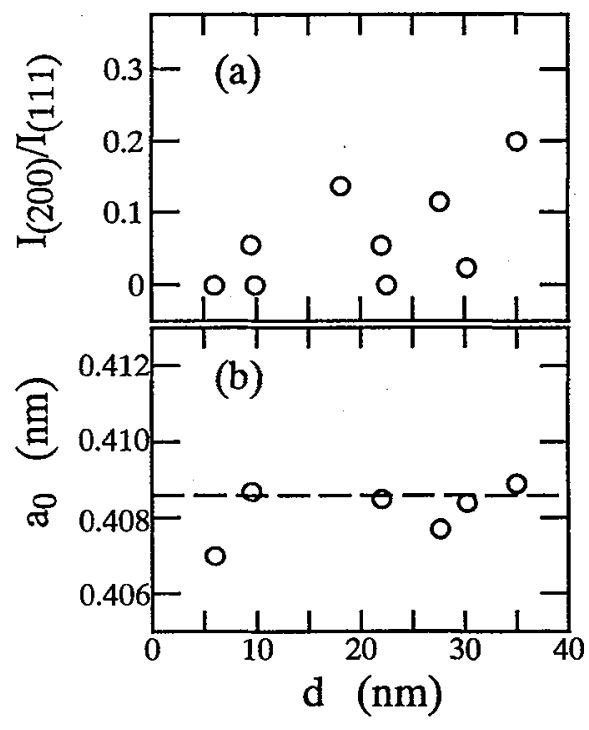

Figure 1. X-ray results observed for $\mathrm{Ag} \mathrm{nm-films}$ on H-terminated $\mathrm{Si}$, (a) $I_{(200)} / I_{(111)}$ and (b) the lattice spacing $a_{0}$ of $\mathrm{Ag}$, where the dashed line denotes $a_{0}$ reported for bulk Ag. See text. 
tendency of decrease with decreasing thickness $d$, where the observed variations in $E_{\mathrm{f}}$ are much larger than the experimental errors in $E_{\mathrm{f}}$ mentioned above. Further, for the $\mathrm{Ag}$ films being thicker than $15 \mathrm{~nm}$, most $E_{\mathrm{f}}$ data lie near or above $E_{\mathrm{f}}$ expected for the $<111>$-oriented model-film (the bold arrow a). These results will be discussed below.

\section{DISCUSSION}

The application of equation (1) must satisfy the following criterions: 1 . homogeneous and continuous film on substrate; 2. perfect adhesion. For the film-on-substrate composite reeds, the film is constraint by the substrate, where the criterion 1 becomes to be not so critical when the asperity ratio is not too high and the fractional area of holes and cracks is negligible. That is, equation (1) predicts that $\Delta f l f$ changes linearly with $d$, indicating that $\Delta f / f$ expected for an inhomogeneous film with mean thickness $d$ and a low asperity ratio is not so different from $\Delta f / f$ of a homogeneous film with $d$. For the present $\mathrm{Ag} \mathrm{nm}$-films, the asperity ratio is as low as 5/100 or $10 / 100$. The criterion 2 predicts that the value of $E_{\mathrm{f}}$ accounted for using equation (1) show a decrease from the intrinsic value of $E_{\mathrm{f}}$ with decreasing adhesion. On the other hand, for the $\mathrm{Ag}$ films being thicker than $15 \mathrm{~nm}$, most $E_{\mathrm{f}}$ data lie near or above $E_{\mathrm{f}}$ expected for the $<111>$-oriented model-film, suggesting that the criterion 2 is satisfied for the thicker nm-films. As will be mentioned later, the criterion 2 may be also satisfied for the thinner nm-films. After the above consideration, one can say that the outline of the $E_{\mathrm{f}}$ data shown in Fig. 2 reflects that of the intrinsic elastic property of the Ag nm-films on H-terminated Si.

The values of $E_{\mathrm{f}}$ accounted from the X-ray results mentioned for Fig. 1(a) lie between the values of $E_{\mathrm{f}}$ expected for the $<111>$ - and the $<110>$-oriented model-films when Young's modulus in the nm-films is assumed to be that in bulk $\mathrm{Ag}$. In contrast, most $E_{\mathrm{f}}$ data observed for $\mathrm{Ag}$ films being thicker than $15 \mathrm{~nm}$ lie near or above $E_{\mathrm{f}}$ expected for the $<111>$-oriented model-film, and with decreasing $d$, the observed values of $E_{\mathrm{f}}$ decrease beyond $E_{\mathrm{f}}$ expected for the $<100>$-oriented model-film.

The decrease in $E_{\mathrm{f}}$ with decreasing $d$ will be discussed at first. For an effect of grain boundary regions on elastic modulus, it is reported that nanocrystalline metals with grain sizes below about $10 \mathrm{~nm}$ show a decrease in elastic modulus by a few tens percents $[13,14]$. In the present $\mathrm{Ag}$ films, grain sizes are as large as $100 \mathrm{~nm}$, suggesting that a probable effect of grain boundary regions on $E_{\mathrm{f}}$ is negligibly small. On the other hand, a probable effect of a near- $\mathrm{Ag} / \mathrm{Si}$-interface region can be expected to increase with decreasing $d$. Tensile stress accounted for from the observed deviation of $a_{0}$ shown in Fig. 1(b) and the assumption of Poisson ratio $v_{\mathrm{f}}$ being that in bulk $\mathrm{Ag}$, predicts a decrease in $E_{\mathrm{f}}$ by a factor of ten percents after [15], which is smaller than the observed decrease in $E_{\mathbf{f}}$. However, in the near-interface region, when the lattice spacing in the film plane is considerably elongated although the lattice spacing normal to the film plane remains nearly unchanged, one can expect a considerable decrease in $E_{\mathrm{f}}$ measured along the film plane.

After the above consideration, as the first step in order to explain the $E_{\mathrm{f}}$ data, we made the parameter fitting of the $E_{\mathrm{f}}$ data using equation (2),

$$
E_{\mathbf{f}}=\left[E_{\mathrm{f}, 0} d_{0}+E_{\mathrm{f}, \mathrm{b}}\left(d-d_{0}\right)\right] / d,
$$

where the film is supposed to consist of the two constituent subregions; the soft interface region with Young's modulus $E_{\mathrm{f}, 0}$ and thickness $d_{0}$, and the remaining region with Young's modulus $E_{\mathrm{f}, \mathrm{b}}$ and thickness $\left(d-d_{0}\right)$. In Fig.2, the curve 1 is fitted to the upper bound of the $E_{\mathrm{f}}$ data where $E_{\mathrm{f}, 0}=3.0 \times 10^{10} \mathrm{~Pa}, d_{0}=6$ 
$\mathrm{nm}$ and $E_{\mathrm{f}, \mathrm{b}}=11.5 \times 10^{10} \mathrm{~Pa}$ are assumed, and the curve $1^{\prime}$ to the lower bound of the $E_{\mathrm{f}}$ data where $E_{\mathrm{f}, 0}$ $=3.0 \times 10^{10} \mathrm{~Pa}, d_{0}=9 \mathrm{~nm}$ and $E_{\mathrm{f}, \mathrm{b}}=9.2 \times 10^{10} \mathrm{~Pa}$ are assumed, respectively. The above model of the soft interface region implicitly assumes the criterion 2 . On the other hand, the departure from the criterion 2 where adhesion decreases with decreasing $d$ can also explain the strong decrease in $E_{\mathrm{f}}$ with decreasing $d$ However, for such a case, the observed deviation of $a_{0}$ shown in Fig.1(b) may be not expected because of a decrease in the constraint.

In Fig.2, with increasing $d$, the lower bound of the $E_{\mathrm{f}}$ data, the curve 1', appears to increase towards $E_{\mathrm{f}}$ expected for the $<111>$-oriented model-film or $E_{\mathrm{f}}$ accounted for using Young's modulus in bulk $\mathrm{Ag}$ and the X-ray results mentioned for Fig. 1(a). That is, most $E_{\mathrm{f}}$ data observed here lie above $E_{\mathrm{f}}$ expected from Young's modulus in bulk Ag. A current theoretical study [6] reports that an effect of surface stress can give rise to an increase in elastic moduli, where biaxial modulus of $\mathrm{Ag}$ referred to the bulk value is higher by a few percents at $6 \mathrm{~nm}$ thick and by about 20 percents at $1 \mathrm{~nm}$ thick. In the present thickness range above $6 \mathrm{~nm}$, the probable effect of surface stress mentioned above appears to hardly explain the observed result. However, when surface stress in a practical film is much larger than that evaluated in [6], one may expect a considerable increase in $E_{\mathrm{f}}$. To clarify this issue as well as the origin of the $d$ dependence of $E_{\mathrm{f}}$ the further work is now in progress.

\section{CONCLUSION}

Young's modulus $E_{\mathrm{f}}$ for polycrystalline $\mathrm{Ag} \mathrm{nm}$-films deposited on H-terminated $\mathrm{Si}$ varies with filmthickness $d$ in the film-thickness range between 6 and $50 \mathrm{~nm}$ : $E_{\mathrm{f}}$ observed for $d$ above about $20 \mathrm{~nm}$ is slightly higher than the upper bound of Young's modulus expected for polycrystalline bulk-films. With decreasing $d, E_{\mathrm{f}}$ decreases beyond the lower bound of Young's modulus expected in bulk oriented-films Plausible models to explain these results are discussed.

\section{Acknowledgement}

The authors are indebted to Dr. Tanimoto (Univ. Tsukuba) for the AFM observation and his help in the course of the experiments. The supply of silicon single crystals from Shin-etsu Semiconductor Ltd (Tokyo, Japan) is gratefully acknowledged. This work is partly supported by a Grant in Aid for Scientific Research from the Sumitomo Foundation (Tokyo, Japan).

\section{References}

[1] Doraiswamy N., Jayaram G. and Marks L.D., Phys. Rev. B, 51(1995), 10167.

[2] Lin X.F., Wan K.L. and Nogami J., Phys. Rev. B, 47(1994), 10947, 13491, 13700.

[3] Luo E.Z., Heun S. Kennedy M., Wollshälger J. and Henzler M., Phys. Rev. B, 49(1994), 4858.

[4] Chou S.-H., Freeman A.J., Grigoras S., Gentle T.M., Delley B. and Wimmer E., J. Che. Phys. 89(1988), 5177.

[5] Koch R., J. Phys: Condens. Matter, 6(1994), 9519.

[6] Streitz F.H., Cammarata R.C. and Sieradzki K., Phys. Rev. B, 49(1994), 10699.

[7] Mizubayashi H., Yoshihara Y. and Okuda S., Phys. Stat. Sol. (a), 129(1992), 475.

[8] Mizubayashi H., Yamaguchi T. and Yoshihara Y., J. Alloys and Compounds, 211/212(1994), 446.

[9] Pelosin V., Badawi K.F. and Branger V., Appl. Phys. Lett., 66(1995), 961.

[10] Sumitomo K., Kobayashi T., Shoji F. Oura K. and Katayams I., Phys. Rev. Lett., 66(1991), 1193.

[11] Oura K., Naitoh M., Yamane J. and Shoji F., Sur.Sci., 230(1990), L151.

[12] Berry B.S and Pritchet A.C, J. Physique, 42(1981), C5-1111.

[13] Korn D., Morsch A., Birringer R., Arnold W. and Gleiter H., J. Physique, 49(1988), C5-769.

[14] Weller M., Diehl J. and Schaefer H.-E., Phil. Mag., 63(1991), 527.

[15] Jones R.S., Slotwinski J.A. and Jintmire J.M., Phys. Rev. B, 45(1992), 13624. 